\title{
Studi Deskriptif Pendampingan Hukum LK3 (Lembaga Konsultasi dan Kesejahateran Keluarga) Dinas Sosial Kabupaten Bengkalis
}

\author{
Juwandi ${ }^{1}$, Daria $^{2}$, Ade Idra Suhara $^{3}$ \\ ${ }^{1}$ Dosen STAIN Bengkalis \\ Email : jujuxpresi.22@gmail.com, \\ ${ }^{2}$ Dosen STAIN Sultan Abdurrahman Kepulauan Riau \\ Email daria@stainkepri.co.id, \\ ${ }^{3}$ Dosen STAIN Bengkalis \\ Email : suharaidra@gmail.com
}

\begin{abstract}
LK3 is an organization that provides consulting services, counseling, information sharing/dissemination, outreach, advocacy, and empowerment for families in a professional manner, including referring targets to other service institutions capable of solving problems more intensively. This LK3 is aimed at families who need assistance in handling psychological, social (psychosocial) problems, as well as individuals, groups, institutions who because of their concern for dealing with family problems. The purpose of this research is for $L K 3$ in Bengkalis Regency to have a community service function, one of which is the existence of a team of experts who assist LK3 service tasks. One of them is a team of legal experts who can carry out their duties in the form of assisting clients with their problems by providing legal solutions in particular. The method used in this research is quantitative descriptive statistics. This means that researchers analyze data based on tables through data collection techniques, one of which is documentation. The results of this study in the form of legal assistance at the LK3 of the Bengkalis Regency Social Service from 2018-2020 experienced a significant increase, namely in 2018 as many as 5 cases, in 2019 as many as 7 cases and in 2020 as many as 23 cases.
\end{abstract}

Keywords : Legal Assistance; LK3 Consultation; Family Welfare Institution

Abstrak. LK3 adalah organisasi yang memberikan pelayanan konsultasi, konseling, pemberian/penyebarluasan informasi, penjangkauan, advokasi, dan pemberdayaan bagi keluarga secara profesional, termasuk merujuk sasaran ke lembaga pelayanan lain yang mampu memecahkan masalahnya secara lebih intensif. LK3 ini ditujukan kepada keluarga yang membutuhkan bantuan penanganan masalah psikologis, sosial (psikososial), maupun individu, kelompok, institusi yang karena kepeduliannya mengatasi masalah keluarga. Adapun tujuan dalam penelitian ini agar LK3 yang berada di kabupaten bengkalis memliki fungsi pelayanan masayarakat salah satunya dengan adanya tim ahli yang membantu tugas-tugas layanan LK3. Salah satunya adalah tim ahli Hukum yang mana dapat melakukan tugasnya dalam bentuk mendampingi klien terhadap permasalahannya dengan memberikan solusi hukum pada khususnya. Metode yang digunakan dalam penelitian ini adalah kuantitatif statistik deskriptif. Artinya peneliti melakukan analisis data berdasarkan tabel melalui teknik pengumpulan data yaitu salah satunya dokumentasi. Hasil penelitian ini berupa pendampingan hukum di LK3 Dinas Sosial Kabupaten Bengkalis dari tahun 2018-2020 mengalami peningkatan yang cukup signifikan yaitu tahun 2018 sebanyak 5 kasus, tahun 2019 sebanyak 7 kasus dan tahun 2020 sebanyak 23 kasus.

Kata Kunci : Pendampingan Hukum; LK3 Lembaga Konsultasi, Kesejahateran Keluarga 


\section{PENDAHULUAN}

Keluarga merupakan unit terkecil di dalam masyarakat, memiliki fungsi utama dalam mencetak generasi penerus bangsa. Jika keluarga menjalankan fungsi dan peranya dengan baik, maka akan menjadi pilar - pilar kemajuan bangsa. Sebaliknya, jika di unit keluarga bermasalah maka akan menjadi permasalahan bagi negara sehingga sulit akan kemajuan bangsa.

Oleh karena itu keluarga semestinya memiliki kesejahteraan baik fisik ataupun materil. Sejalan dengan Undang-undang Nomor 52 Tahun 2009 mendefinisikan bahwa ketahanan dan kesejahteraan keluarga adalah kondisi keluarga yang memiliki keuletan dan ketaguhan serta mengandung kemampuan fisik serta materil guna hidup mandiri dan mengembangkan diri dan keluarganya untuk hidup harmonis dalam meningkatkan kesejahteraan kebahagiaan lahir dan batin. Hanya saja, tidak seluruh keluarga yang mampu menjalankan peran sesuai dengan fungsi tersebut.

Keluarga yang mengalami hambatan atau kesulitan sehingga tidak mampu menjalankan peran dan fungsinya disebuat PMKS. Lebih lanjut, Dinas Kesejahteraan Sosial Republik Indonesia, mengklasifikasikan keluarga bermasalah sebagai Penyandang Masalah Kesejahteraan Sosial (PMKS) yaitu seseorang atau keluarga yang karena suatu hambatan, kesulitan atau gangguan tidak dapat melaksanakan fungsi sosialnya dan karenanya tidak dapat menjalin hubungan yang serasi dan kreatif dengan lingkungannya sehingga tidak dapat memenuhi kebutuhan hidupnya (jasmani, rohani dan sosial) secara memadai dan wajar. Upaya yang telah dilakukan pemerintah saat ini untuk mengatasi permasalahan tingginya kasus keluarga keluarga bermasalah salah satunya adalah dengan membentuk badan-badan yang secara khusus bertujuan untuk meminimalisir bahkan mengatasi permasalahan tersebut (Siregar, 2018).

Salah satu instansi pemerintah yang memiliki peran dalam membantu pemerintah adalah Dinas sosial. Dinas Sosial yang berupaya membantu hal tersebut salah satunya adalah Dinas Sosial Provinsi Riau. Adapun fokus Penyelenggaraan Kesejahteraan Sosial merupakan kebijakan Pemerintah Provinsi Riau yang menjadi urusan Dinas Sosial Provinsi Riau dengan fokus pada 7 (tujuh) permasalahan sosial yakni Kemiskinan, Keterlantaran, Kecacatan, Ketunaan Sosial dan Penyimpangan Perilaku, Keterpencilan, Korban Bencana serta Tindak Korban Kekerasan dan Pekerja Migran, baik yang bersifat primer maupun akibat/dampak non sosial. Dinas Sosial Provinsi Riau sebagai Satuan Kerja Perangkat Daerah (SKPD) memiliki peran untuk melaksanakan urusan bidang sosial dan memiliki tugas pokok dalam penanganan terhadap Penyandang Masalah Kesejahteraan Sosial (PMKS) (Siregar, 2018).

Adapun Lembaga yang bernaung dibawah dinas sosial yang menangani permasalahan kesejahteraan keluarga adalah LK3. LK3 adalah organisasi yang memberikan pelayanan konsultasi, konseling, pemberian/penyebarluasan informasi, penjangkauan, advokasi, dan pemberdayaan bagi keluarga secara profesional, termasuk merujuk sasaran ke lembaga pelayanan lain yang mampu memecahkan masalahnya secara lebih intensif. LK3 ini didirikan oleh pemerintah, pemerintah daerah atau masyarakat, dimana keberadaan LK3 diharapkan dapat menjadi centre link terhadap semua layanan keluarga. LK3 memiliki sasaran pelayanan yaitu keluarga yang membutuhkan informasi dan advokasi dalam pengembangan kualitas keluarga. LK3 ini ditujukan kepada keluarga yang membutuhkan bantuan penanganan masalah psikologis, sosial (psikososial), maupun individu, kelompok, institusi yang karena kepeduliannya mengatasi masalah keluarga. Permasalahan yang ditangani oleh LK3 meliputi kasus dalam lingkup keluarga seperti kasus Kekerasan dalam Rumah Tangga (KDRT), masalah psikososial lanjut usia, disabilitas, anak, dan termasuk kekerasan anak (Daniasari, dkk 2020)

Adapun yang menjadi fokus permasalahan LK3 merupakan lembaga yang secara terpadu bernaung dibawah Dinas Sosial yang terdiri atas LK3 dengan basis Kabupaten/kota, LK3 berbasis masyarakat dan LK3 berbasis perguruan tinggi. LK3 berbasis kota merupakan LK3 yang secara khusus menangani masalah psikososial individu, keluarga maupun masyarakat dalam lingkup hanya satu kabupaten/kota saja, sedangkan LK3 berbasis masyarakat cenderung dikelola untuk melayani masalah psikososial di lingkup yang lebih luas yaitu tingkat provinsi, sedangkan LK3 berbasis perguruan tinggi merupakan LK3 yang bersifat umum yang dimiliki suatu perguruan tinggi untuk 
melayani masyarakat secara umum dan sebagai media belajar bagi mahasiswa secara khusus (Siregar, 2018).

Nassrie, (2004) Keberadaan LK3 pada tahun 2010 sebanyak 485 yang tersebar di seluruh Dinas Sosial/Instansi kabupaten/ Kpta dan 66 LK3 berbasis masyarakat yang tersebar di 28 provinsi (dalam Samsudin, 2019). Salah satu yang memiliki peran dalam meminimalisir permasalahan keluarga di tingkat Kabupaten adalah LK3 kabupaten Bengkalis yang turut serta intensif dalam penanganan permasalahan keluarga yang terjadi di Kabupaten Bengkalis.

LK3 yang berada di kabupaten bengkalis memliki fungsi pelayanan masayarakat salah satunya dengan adanya tim ahli yang membantu tugas-tugas layanan LK3. Salah satunya adalah tim ahli Hukum. Tim ahli hukum melakukan tugasnya dalam bentuk mendampingi klien terhadap permasalahannya dengan memberikan solusi hukum pada khususnya.

\section{METODE PENELITIAN}

Penelitian ini menggunakan pendekatan kuantitatif metode statistik deskriptif. Artinya peneliti menganalisis data atau menggambarkan data yang telah terkumpul sebagaimana adanya tanpa bermaksud membuat kesimpulan yang berlaku umum atau generalisasi (Sugiyono, 2010:208). Penyajian data dalam statistik deskriptif dapat berupa tabel, grafik, diagram lingkaran, piktogram, mean, median, modus, dll. Untuk pengumpulan data dalam penelitian ini menggunakan teknik dokumentasi, wawancara, dan observasi.

\section{HASIL PENELITIAN DAN PEMBAHASAN}

Berdasarkan hasil analisa data, temuan penelitian maka dapat diuraikan secara rinci yaitu berupa distribusi frekuensi dari jenis kelamin. Berikut gambaran responden berdasarkan jenis kelamin

Tabel 1 Karakteristik Sampel berdasarkan Jenis Kelamin

\begin{tabular}{|c|c|c|c|}
\hline No & Jenis Kelamin & Jumlah & Persentasi \\
\hline 1 & Laki-laki & 17 & $48,57 \%$ \\
\hline 2 & Perempuan & 18 & $51,43 \%$ \\
\hline & Total & 35 & 100 \\
\hline
\end{tabular}

Berdasarkan data jumlah presentasi di atas terdapat jumlah permasalahan keluarga di Kabupaten Bengkalis yang membutuhkan pendampingan ahli hukum yaitu berjumlah 35 orang dengan rincian jumlah laki-laki 17 orang sebesar $48,57 \%$ dan perempuan 18 orang sebesar $51,43 \%$. Pendampingan sosial merupakan suatu proses relasi sosial antara pendamping dengan klien yang bertujuan untuk memecahkan masalah, memperkuat dukungan, mendayagunakan berbagai sumber dan potensi dalam pemenuhan kebutuhan hidup, serta meningkatkan akses klien terhadap pelayanan sosial dasar, lapangan kerja, dan fasilitas pelayanan publik lainnya (Departemen Sosial RI, 2009: 122). Berdasarkan data dihubungkan dengan teori pendampingan sosial tersebut maka di Kabupaten Bengkalis membutuhkan pendampingan terutama dibidang hukum. Pendampingan ini bertujuan untuk mendampingi klien baik berjenis kelamin laki-laki maupun perempuan terhadap permasalahannya dan diberikan solusi hukum dari pendamping sesuai tugas, pokok dan fungsinya. 
Tabel 2. Data jenis permasalahan yang membutuhkan pendampingan hukum dan persentasenya tahun 2018

\begin{tabular}{|c|l|c|c|}
\hline No & Jenis Permasalahan Hukum & Jumlah & Persentase \\
\hline 1 & Perceraian & - & - \\
\hline 2 & KDRT & 3 & 60 \\
\hline 3 & $\begin{array}{l}\text { Kenakalan Remaja (Bullying, } \\
\text { Narkoba, Kenakalam remaja) }\end{array}$ & 2 & 40 \\
\hline 4 & Disabillitas & - & - \\
\hline & \multicolumn{2}{|l}{5} & 100 \\
\hline
\end{tabular}

Berdasarkan jumlah presentasi dari data diatas pada tahun 2018 diperoleh jumlah kasus LK3 yang membutuhkan pendampingan ahli bidang hukum yaitu 5 kasus dengan jenis permasalahan antara lain KDRT sebanyak 3 orang sebesar $60 \%$, kasus kenakalan remaja sebanyak 2 kasus sebanya $40 \%$. Pendampingan hukum yang diberikan kepada klien bukan hanya dalam bidang hukum saja tapi ada dalam bentuk memperkuat dukungan, mendayagunakan berbagai sumber dan potensi dalam pemenuhan kebutuhan hidup, serta meningkatkan akses klien terhadap pelayanan sosial dasar, lapangan kerja, dan fasilitas pelayanan publik lainnya dalam usaha memecahkan masalah serta mendorong tumbuhnya inisiatif dalam proses pengambilan keputusan, sehingga kemandirian klien secara berkelanjutan dapat diwujudkan

Tabel 3. Data jenis permasalahan yang membutuhkan pendampingan hukum dan persentasenya tahun 2019

\begin{tabular}{|c|l|c|c|}
\hline No & \multicolumn{1}{|l|}{ Jenis Permasalahan Hukum } & Jumlah & Persentase \\
\hline 1 & Perceraian & - & \\
\hline 2 & KDRT & 4 & 57,1 \\
\hline 3 & $\begin{array}{l}\text { Kenakalan Remaja (Bullying, } \\
\text { Narkoba, Kenakalam remaja) }\end{array}$ & 3 & 42,9 \\
\hline 4 & Disabillitas & - & \\
\hline & Total & 7 & 100 \\
\hline
\end{tabular}

Berdasarkan jumlah presentase dari data diatas pada tahun 2019 diperoleh jumlah kasus LK3 yang membutuhkan pendampingan ahli bidang hukum yaitu 7 kasus dengan jenis permasalahan antara lain KDRT sebanyak 4 kasus sebesar $57,1 \%$, kasus kenakalan remaja sebanyak 3 kasus sebanya 42,9\%. Berdasarkan data tahun 2019 terjadi peningkatan 2 kasus yang membutuhkan pendampingan hukum yaitu pada tahun 2018 sebanyak 5 kasus menjadi 7 kasus. Pendampingan adalah suatu proses pemberian kemudahan (fasilitas) yang diberikan pendamping kepada klien dalam mengidentifikasi kebutuhan dan memecahkan masalah serta mendorong tumbuhnya inisiatif dalam proses pengambilan keputusan, sehingga kemandirian klien secara berkelanjutan dapat diwujudkan (Direktorat Bantuan Sosial, 2007: 4).

Tabel 4. Data jenis permasalahan yang membutuhkan pendampingan hukum dan persentasenya tahun 2020

\begin{tabular}{|c|l|c|c|}
\hline No & Jenis Permasalahan Hukum & Jumlah & Persentase \\
\hline 1 & Perceraian & 5 & $21.7 \%$ \\
\hline 2 & KDRT & 6 & $26,1 \%$ \\
\hline 3 & $\begin{array}{l}\text { Kenakalan Remaja (Bullying, } \\
\text { Narkoba, Kenakalam remaja) }\end{array}$ & 9 & $39.1 \%$ \\
\hline
\end{tabular}




\begin{tabular}{|c|l|c|c|}
\hline 4 & Disabillitas & 3 & $13,1 \%$ \\
\hline & Total & 23 & $100 \%$ \\
\hline
\end{tabular}

Berdasarkan jumlah presentase dari data diatas pada tahun 2020 diperoleh jumlah kasus LK3 yang membutuhkan pendampingan ahli bidang hukum yaitu 23 kasus dengan jenis permasalahan antara lain perceraian sebanyak 5 kasus sebesar $21.7 \%$, kasus KDRT sebanyak 6 kasus sebesar 26.1 $\%$, kasus kenakalan remaja sebanyak 9 kasus sebanya $39.1 \%$, kasus disabilitas 3 sebesar 13,1\%. Pekerja sosial adalah sebagai orang yang memiliki kewenangan keahlian dalam menyelenggarakan berbagai pelayanan sosial (Budhi Wibhawa, 2010: 52). Pendampingan hukum di LK3 Dinas Sosial Kabupaten Bengkalis dari tahun 2018-2020 mengalami peningkatan yang cukup signifikan yaitu tahun 2018 sebanyak 5 kasus, tahun 2019 sebanyak 7 kasus dan tahun 2020 sebanyak 23 kasus. Dapat dirumuskan bahwa pendampingan hukum bagian dari pekerja sosial di LK3 Dinas Sosial Kabupaten bengkalis. Pendampingan hukum merupakan seseorang yang mempunyai kompetensi dalam menyelenggarakan berbagai pelayanan sosial baik di instansi pemerintah maupun di instansi swasta lainnya.

Berdasarkan pengertian tentang pendampingan dan pekerja sosial, sehingga dapat diartikan bahwa pendampingan pekerja sosial terhadap klien adalah proses relasi sosial antara pekerja sosial yang memiliki kompetensi dalam menyelenggarakan berbagai pelayanan sosial baik di instansi pemerintah maupun di instansi swasta lainnya dengan klien dalam bentuk memperkuat dukungan, mendayagunakan berbagai sumber dan potensi dalam pemenuhan kebutuhan hidup, serta meningkatkan akses klien terhadap pelayanan sosial dasar, lapangan kerja, dan fasilitas pelayanan publik lainnya dalam usaha memecahkan masalah serta mendorong tumbuhnya inisiatif dalam proses pengambilan keputusan, sehingga kemandirian klien secara berkelanjutan dapat diwujudkan.

Tujuan Pendampingan pekerja sosial terhadap klien berkaitan erat dengan hakikat pekerjaan sosial dimana merupakan suatu profesi yang bertanggung jawab dalam memperbaiki dan mengembangkan interaksi antar individu, kelompok dan atau masyarakat, sehingga mereka dapat melaksanakan tugas kehidupannya, dapat mengatasi permasalahan atau kesulitan yang dihadapi, dan mencapai kesejahteraan dalam kehidupannya (Istian Hermawati, 2001: 14). Permasalahan atau kasus yang ada di LK3 Dinas Sosial Kab. Bengkalis yang membutuhkan pendampingan hukum adalah kasus perceraian, KDRT, kenakalan remaja dan disabilitas. Masing-masing kasus diberikan pendampingan hukum dari LK3 Dinas Sosial Kab. Bengkalis melalui ahli yang berkompeten dibidangnya. Tujuannya adalah agar bisa memberikan solusi dan menyelesaikan masalah klien.

\section{KESIMPULAN}

1. Berdasarkan data yang diperoleh adanya peningkatan dari perolehan kasus yang ditangani secara hukum oleh LK3 yaitu 5 kasus di tahun 2018, 7 kasus di 2019, dan 23 kasus di tahun 2020.

2. Jumlah kasus yang membutuhkan pendampingan hukum meningkat di tahun 2020 yaitu di kasus perceraian, KDRT, kenakalan remaja, disabilitas.

\section{DAFTAR PUSTAKA}

Daniasari, A \& Setiamanah, M, D. 2020 Pemanfaatan Pelayanan Sosial Lembaga Konsultasi Kesejahteraan Keluarga Oleh Anak Korban Tindak Kekerasan di Kota Cimahi Provinsi Jawa Barat, Jurnal REHSOS : Jurnal Ilmia Rehabilitasi Sosial Vol. 2, No. 1

Samsudin, D, 2019. Peran Lembaga Konsultasi Kesejahteraan Keluarga (LK3) Mitra Sejahtera dalam Upaya Pencegahan Angka Perceraian Di kota Manna Tesis Institut Agama Islam Negeri (IAIN) Bengkulu

Samsudin, D, 2019. Peran Lembaga Konsultasi Kesejahteraan Keluarga (LK3) Mitra Sejahtera dalam Upaya Pencegahan Angka Perceraian Di kota Manna Jurnal Qiyas Vol 4, No. 2

Siregar, S. 2018. Peran Lembaga Konsultasi Kesejahteraan Keluarga TAT TWAM ASI Dalam Penanganan Masalah Keluarga, Jurnal JOM FISIP Vol. 5 
Sukardi, 2015. Metode Penelitian Pendidikan Kompetensi dan Praktiknya, Bumi Aksara Undang-undang Republik Indonesia No 52 tahun 2009 tentang penyandang di unduh Januari 2021 Peraturan Menteri Sosial RI No 8 Tahun 2012 tentang Pedoman Pendataan dan Pengelolaan Data Penyandang Masalah Kesejahteraan Sosial dan Potensi dan Sumber Kesejahteraan Sosial Peraturan Menteri Sosial RI No 16 Tahun 2013 tentang Lembaga Konsultasi Kesejahteraan Keluaraga Peraturan Menteri Sosial RI No 25 Tahun 2017 tentang Lembaga Konsultasi Kesejahteraan Keluarga 